\title{
Unmasking Students' Learning Experiences during Coronavirus Pandemic
}

\author{
Hemlata V. Gaikwad, Sushma S. Kulkarni² \\ ${ }^{1}$ Department of Management Studies, Rajarambapu Institute of Technology, Rajarmnagar, MS,India \\ ${ }^{2}$ Department of Civil Engineering, , Rajarambapu Institute of Technology, , Rajarmnagar, MS,India \\ ${ }^{1}$ hemlata.gaikwad@ritindia.edu \\ ${ }^{2}$ sushma.kulkarni@ ritindia.edu
}

\begin{abstract}
Indian education system is consistently evolving since gurukul methods to blended modes, but most of the educational institutes from pre-primary to universities are still following the traditional methods of imparting knowledge. Professional education institutes have adopted blended teaching and learning methods by offering MOOCs through platforms like NPTEL, Coursera, Udemy, EdX and many more. Professors mostly from IITs and from few other institutes are creating these courses in India. A normal faculty from higher educational institute providing professional education is still not creating or delivering courses online. But online teaching remained the only option when educational institutes across globe were closed because of covid-19 pandemic impacting all stakeholders. Hence, it was a need of the time to understand students' perceptions regarding online learning. A number of studies have been conducted on students' perception on learning effectiveness in online teaching since Covid-19 closures of institutes, but very few of them have tried to capture the psychological aspects. The present study has tried to bridge this gap. It is performed in a technical educational institute in western Maharashtra.271 students from three programs participated in the study. A survey instrument designed by authors was used to collect the responses through Google forms. The article includes an analysis of the students' perceptions and categorizes the benefits and drawbacks identified by the students. It is identified that online learning helps in improving the student's regularity in attending the lectures and is more convenient than physical classrooms. The students perceive online learning creates physical stress. At the same time learning gets hampered by comparatively more distractions and technical difficulties. The insights developed will provide valuable information to faculties and administrators in improving the student learning
\end{abstract}

Keywords: Online Learning ,Inclass learning, Psychological aspects, Technical Education.

\footnotetext{
Hemlata V. Gaikwad

Department of Management Studies, Rajarambapu

Institute of Technology, Rajarmnagar, MS,India

hemlata.gaikwad@ritindia.edu

Introduction :
}

Indian education system is consistently evolving since gurukul methods to blended modes. Face to face learning has been the most common method used in India for educating students from nursery to the doctorate level. Ancient India followed gurukul system wherein the students (shishyas') went to the teacher's (spiritual guru) house to learn. It was the residential system whose origin dates back to 5000 B.C. in India. This education system not only helped impart knowledge, but also taught the life skills to the students. The guru taught everything the shishya wanted to learn like Sanskrit, holy scriptures, Mathematics, Metaphysics to arts-related to warfare. This was followed by modern education system where students and teachers get collected at the school, college, or university and the teaching and learning happens. Modern education system was brought to India by Lord Macaulay in 1830s [1]. In this method teaching got confined to classrooms and the link with nature got broken. Abilities like life skills, interpersonal skills got neglected. Last decade saw a major change when Bodies like Central board of secondary education CBSE) introduced life skills, recommended by World Health Organization (WHO) [2], in their curriculum. Experiential learning model got adopted by most of the schools and colleges. In 2013, Ministry of Human Resource Development (MHRD), came out with the National Skills Qualification Framework [3] - a competency based quality assurance framework providing multiple pathways vertically and horizontally for all levels. Government emphasized use of Information and communications technology (ICT) to make the learning more effective. But, the education system in India is still following the traditional methods of imparting knowledge. With a big digital divide, it was not feasible to move to modern methods of teaching using internet and smart infrastructure.

Technical institutes in India realized at an early stage that the traditional methods of teaching are not sufficient to bring in the desired change in the graduates and making them industry ready. Experiential learning models were used to impart knowledge and skills. In 2014, when India became a signatory member of Washington Accord, Outcome Based Education Model was adopted by engineering institutes in India[3]. This encouraged use of innovative pedagogical tools to achieve the outcomes, but the methods remained traditional. In 2016, the MHRD Government of India introduced SWAYAM where teachers from premium institutes like IITs, IIMs and Central Universities offered online courses. Nine coordinators were appointed by MHRD to ensure the quality of these courses 
where NPTEL is a coordinator for engineering institutes [4] The introduction of MOOCs by NPTEL brought a major change in the delivery of course content in engineering institutes. It gave an experience of online learning to the teachers and students pan India. Nisha and Senthil (2015) opined that MOOCs and use of technology has changed the face of education in India by providing distance learning through online modes[5]. Bandalara ( 2018) in his study concluded that MOOCs are playing a significant role in transforming higher education in Asia [6].This was a positive change, as this enabled students and teachers in engineering institutes across India to avail online courses and improve their learning. Developing a MOOC and offering them still remained a privilege of premier institutes. The faculties at other engineering institutes are still not prepared and ready to create and offer MOOCs - the reason could be lack of infrastructural facilities or their capabilities, as most of them are not trained for teaching online ( Gaikwad, Kulkarni and Pardeshi , 2020) [7].

\section{Transition to Online Teaching}

On $11^{\text {th }}$ March World Health Organization (WHO) declared occurrence of a pandemic (Virtual press conference on COVID-19, WHO). In a preventive response to the potential outbreak, all educational institutes in India from pre-primary to highest degree providers were suddenly asked to close from $16^{\text {th }}$ March 2020. On $24^{\text {th }}$ March 2020, the government of India announced a nationwide lockdown for 21 days as a preventive measure against covid-19 spread. The teachers and students including other stakeholders were totally unprepared for this sudden closure. On 20th March 2020, the Ministry of Human Resource Development ( MHRD) issued a circular requesting all state and union territory administrators to promote digital learning so that students can continue their learning by making full use of the available digital/e-learning platforms during the period educational institutions are closed as a precautionary measure to fight Covid -19 .SWAYAM and SWAYAMPRABHA were recommended for higher education. As a result there was an overnight transition to online teaching and learning. Like teachers, even students were unprepared for this sudden change. There being no other alternative, students had to adapt to this change.

The present article has tried to capture the experiences of students during this shift to online learning. Also, the study compares the In-class and online learning experiences to identify the positive and negative impact of the shift, so as to suggest strategies to make the learning experience most effective for students.

\section{Literature Review}

Distance and online learning experiences had been an area of interest by the researchers since decades, but the same had been increased post pandemic. We carried out a systematic literature survey to identify the extent of coverage in India. We used four important and largest databases viz. SCOPUS, Web of Science, JSTOR and Sage database. We used three keywords

$((($ Online+learning+during+covid+19) $)+$ AND $+(($ engineerin $\mathrm{g},+$ technology+and+management $))+$ AND + India $))$. The same was obtained by changing keywords like coronavirus for Covid 19 etc.

Following is the summary of results obtained.

\begin{tabular}{|l|l|l|l|l|}
\hline Database & \multicolumn{2}{l}{ Results } & \multicolumn{2}{l|}{} \\
\hline Keyword & $\begin{array}{l}\text { Online } \\
\text { Learnin } \\
\text { g during } \\
\text { covid-19 }\end{array}$ & $\begin{array}{l}\text { Engineering, } \\
\text { Technology } \\
\text { and } \\
\text { Managemen } \\
\mathrm{t}\end{array}$ & $\begin{array}{l}\text { Indi } \\
\mathrm{a}\end{array}$ & $\begin{array}{l}\text { Number } \\
\text { of } \\
\text { Relevan } \\
\mathrm{t} \text { papers }\end{array}$ \\
\hline SCOPUS & 618 & 77 & 14 & 3 \\
\hline $\begin{array}{l}\text { Web of } \\
\text { Science }\end{array}$ & 244 & 1 & 0 & 0 \\
\hline JSTOR & 19134 & 18 & 13 & None \\
\hline SAGE & 770 & 106 & 28 & 3 \\
\hline
\end{tabular}

Table No. 1 : Results of Literature Search

It was observed that a lot of research is being conducted during the period of lock down impacted by Coronavirus, most of it is focussed on online and distance teaching. The learning processes are not much focussed. We analysed the five most relevant papers found in the found from the literature search of four largest databases.

The analysis of these papers reveal that transition to online learning due to the pandemic was a forced one and students preferred physical classrooms over virtual classrooms. The studies also revealed that there is a connection gap which occurs in online learning making interactions limited. Also, the digital divide poses issues of connectivity and digital literacy in some cases.

None of the studies discussed the psychological aspects. Only one or two studies discussed effectiveness of online learning as perceived by the students in higher education. One study was conducted in state of Maharashtra in India revealing health issues reported by the students while learning online.

The summary of the papers is presented in Table No. 2 . 


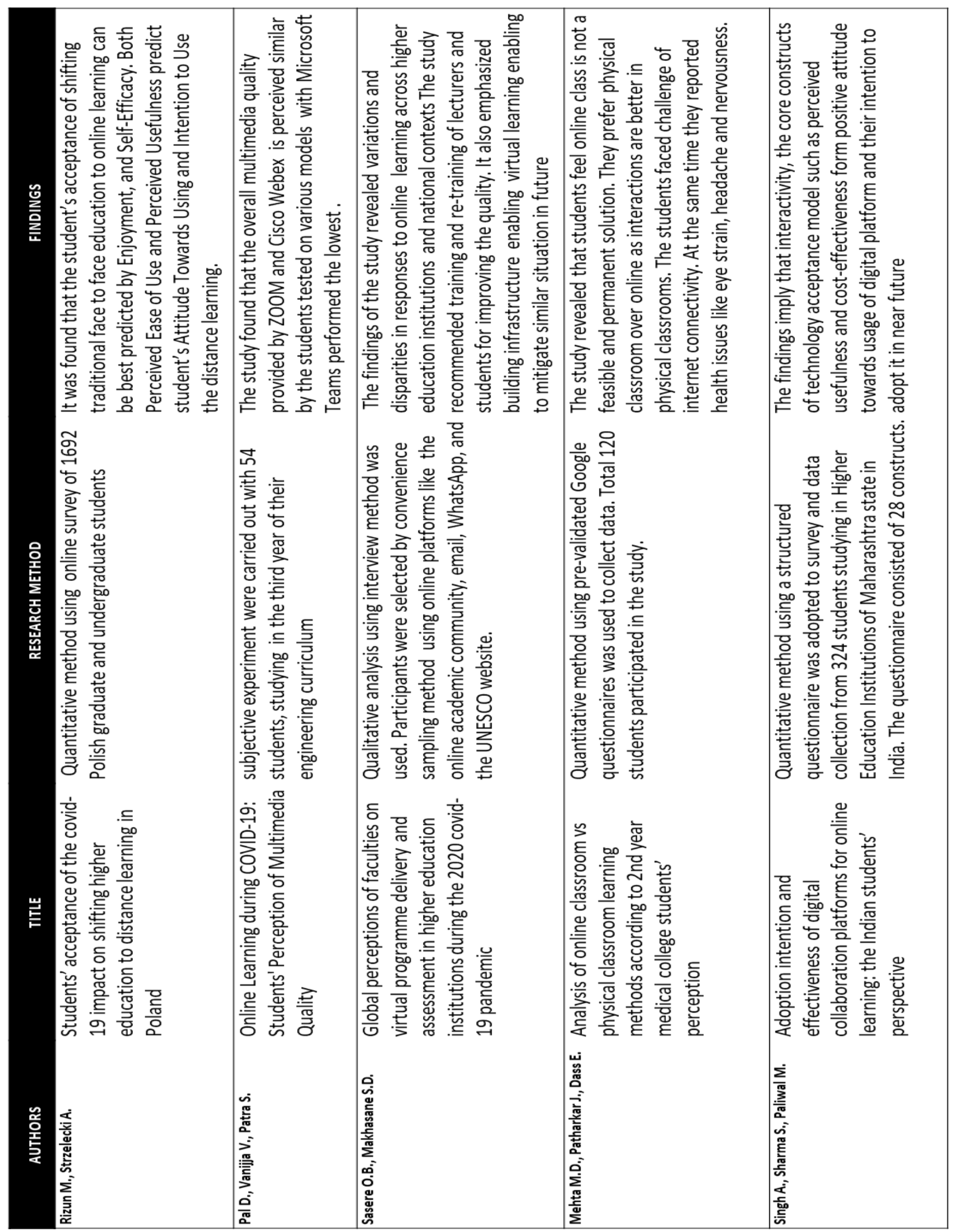


Journal of Engineering Education Transformations, Volume 34, January 2021, Special issue, eISSN 2394-1707 Thus, the present study intended to include the psychological aspects of the learners. Also, apart from comparing the online and physical classroom learning in terms of effectiveness. Also, the study has tried to capture the challenges faced by the learners in online classrooms. The study was conducted at Rajarambapu Instititute of Technology, western Maharashtra, India. The respondents were students pursuing engineering. (graduate, postgraduate and diploma) and management courses. Figure 1 gives the profile of the respondents.

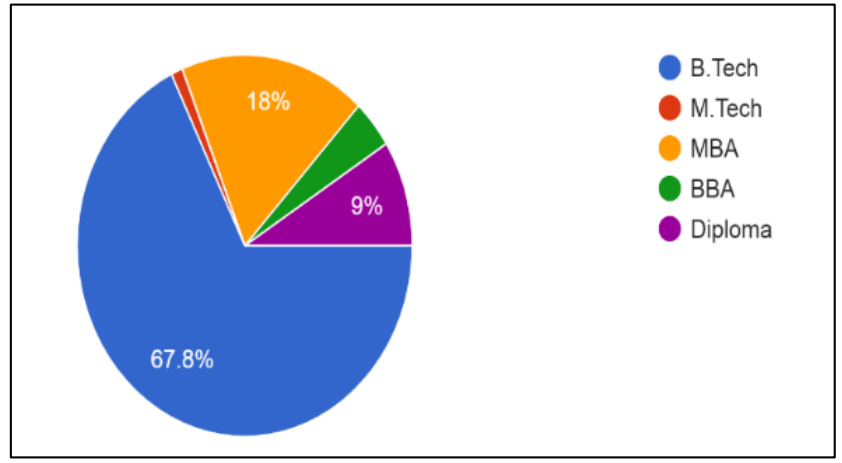

Figure No. 1 : Profile of the respondents

\section{Methodology :}

The study being exploratory in nature, a survey instrument containing 23 items on a likert scale was used besides the demographic profile of the respondents. A total of 271 students participated in the study voluntarily. The instrument was validated with a pilot study. The reliability was also checked and the Cronbach alpha was 0.92 indicating that the instrument was reliable. The data was collected through Google forms in the month of July 2020.Principal Component analysis was used to identify the major factors impacting the experiences. A correlation matrix of intervariables was developed. We estimated the factor loadings to meet the recommended criteria of 0.60 and above. The factors were subjected to direct Oblimin rotation to enable higher interpretability of the dimensions. The KaiserGuttman criterion suggesting Eigen value $>1.0$ for identifying important factors was used. Catell's Scree test was referredfor identifying statistically significant factors.

\section{Findings and Discussion:}

The findings of the study are presented in this section. The perception of students is analysed through the responses obtained during the survey. The psychological aspects were captured through short open ended questions in the instrument. Around $71 \%$ of the students had no prior experiences of online learning and had to suddenly transit to the same when pandemic occurred. Figure 2 depicts the experiences of the students in online learning.

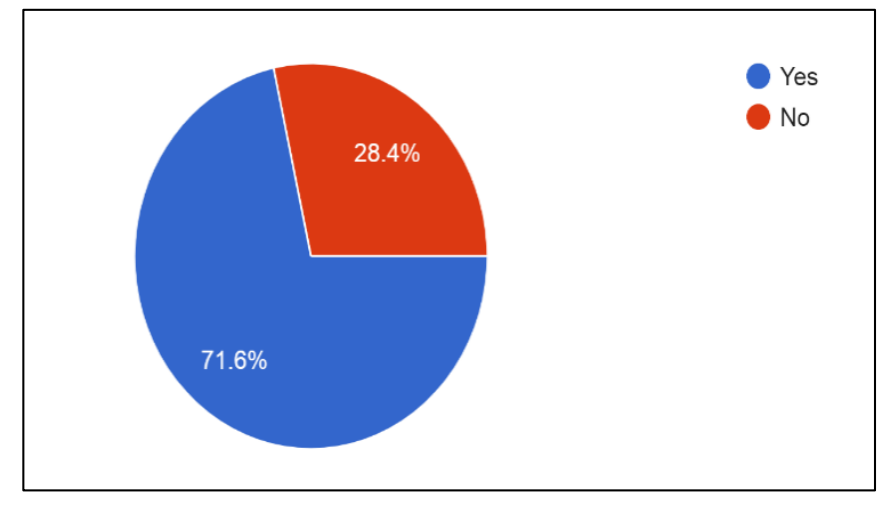

Figure No. 2 Prior experience of online learning

The students having the prior online learning experience used various online learning platforms like coursera, udemy, alison, EdX etc. For learning through other providers they had used ZOOM, Google meet or Microsoft teams also. Figure 3 displays the details of the same.

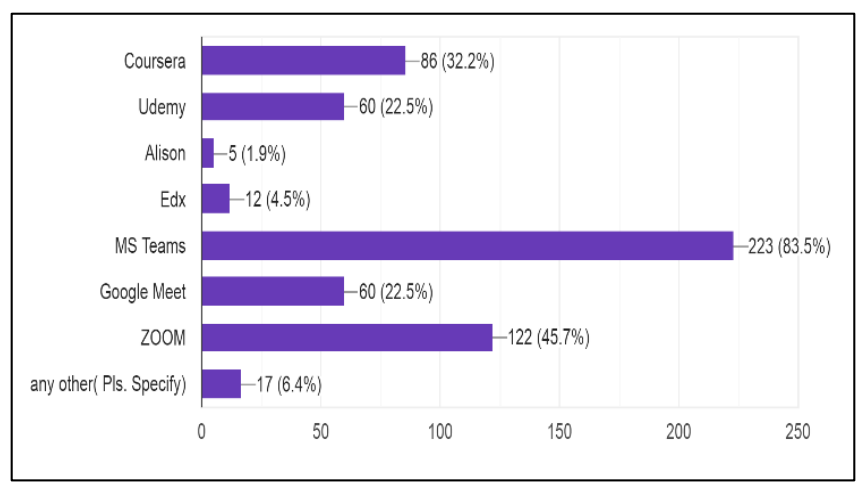

\section{Figure No. 3: Platforms used by respondents for online learning}

The students used various devices for accessing these courses. As most of them belonged to rural areas and farmer's families, used their mobiles to log in the courses. Figure 4 shows the details of the devices used to access the courses and learning online.

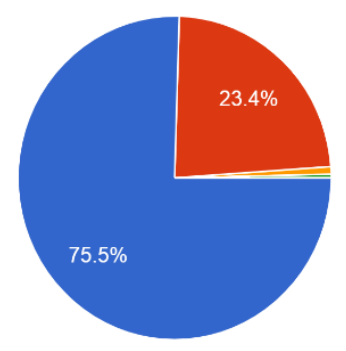

Figure No.4: Device used for accessing online learning 
It is observed that around $71 \%$ of the students had online learning experience and all of the are tech savvy, as at RIT the educational material, assignments ,internal assessments are carried out using various learning management systems.

\section{Effectiveness of Online Learning Vs. In-class Learning}

All 23 items were used for PCA . The correlation matrix identified nine items explaining $76 \%$ of the variance. The factor loadings of these nine items are depicted in table 3.The highest loading is of level of convenience in online learning( 0.852) followed by promoting regularity in attending classes $(0.845)$. Other loadings were between 6 to 7. All loadings were significant with $p<0.05$. This shows that students perceive two factors viz. convenience and regularity as important factors contributing to effectiveness of online learning.

\begin{tabular}{|l|c|}
\hline \multicolumn{1}{|c|}{ Item } & Loading \\
\hline $\begin{array}{l}\text { Establishes an effective } \\
\text { communication }\end{array}$ & .605 \\
\hline Level of Convenience & $\mathbf{8 5 2}$ \\
\hline $\begin{array}{l}\text { Promotes participation and } \\
\text { interaction }\end{array}$ & .563 \\
\hline $\begin{array}{l}\text { Effectiveness of individual } \\
\text { mentorship and personal attention } \\
\text { to learning needs }\end{array}$ & .624 \\
\hline $\begin{array}{l}\text { Promotes regularity in attending } \\
\text { classes }\end{array}$ & $\mathbf{. 8 4 5}$ \\
\hline $\begin{array}{l}\text { Effective exchange of learning and } \\
\text { assessment material }\end{array}$ & .632 \\
\hline $\begin{array}{l}\text { Developing Connect and learning } \\
\text { with peers/classmates }\end{array}$ & .635 \\
\hline $\begin{array}{l}\text { Off - course interactions with peers } \\
\text { for mind freshening }\end{array}$ & .672 \\
\hline $\begin{array}{l}\text { Developing interpersonal and other } \\
\text { leadership skills }\end{array}$ & .616 \\
\hline
\end{tabular}

\section{Table No. 4 : Factor one loadings}

The extracted factors reveal that the online learning is more effective as compared to physical classrooms as the students perceive it to be more convenient. Also, they feel that they can be more regular in online classes as compared to physical ones. This bring forth the point that management and faculties should analyse why physical classrooms are not convenient to students and strategies must be planned to achieve the same.

\section{Challenges of online learning:}

The second factor consisted of items related to challenges faced during online learning. PCA identified 9 factors concerning the challenges faced by the students. The same were also identified as challenges by the respondents.
The weightage given by respondents are shown in the Figure 5.

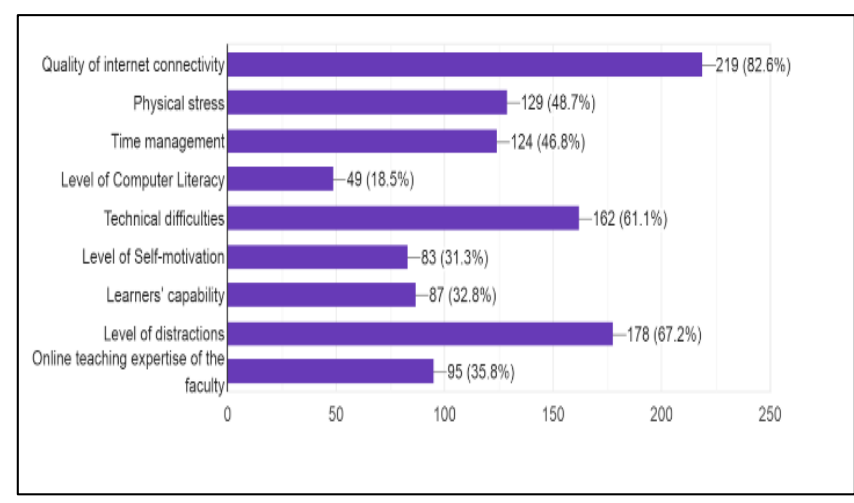

Figure No. 5 : Challenges of online learning as perceived by respondents

The correlation matrix for the challenges also identified nine items explaining $72 \%$ of the variance. The factor loadings of these nine items are depicted in table 4.The highest loading is for physical stress in online learning( 0.935) followed by technical difficulties in attending classes (0.903) and Level of distractions being the third important factor with a loading of 0.898. Other loadings were between 6 to 7. All loadings were significant with $\mathrm{p}<0.05$.

\begin{tabular}{|l|l|}
\hline \multicolumn{1}{|c|}{ Item } & Loading \\
\hline $\begin{array}{l}\text { Establishes an effective } \\
\text { communication }\end{array}$ & 0.675 \\
\hline Physical stress & $\mathbf{0 . 9 3 5}$ \\
\hline Time management & 0.654 \\
\hline Level of Computer Literacy & 0.633 \\
\hline Technical difficulties & $\mathbf{0 , 9 0 3}$ \\
\hline Level of Self-motivation & 0.704 \\
\hline Learners' capability & 0,678 \\
\hline Level of distractions & $\mathbf{0 . 8 9 8}$ \\
\hline $\begin{array}{l}\text { Online teaching expertise of the } \\
\text { faculty }\end{array}$ & 0.656 \\
\hline
\end{tabular}

Table no. 5 Factor two Loadings

The three identified factors indicate that sitting in front of an electronic device continuously for 4-5 hors cause physical stress in students. At the same time, the students are facing technical difficulties like power shortages, internet unavailability or low bandwidth etc. which posits a challenge to effectiveness of online learning. The distractions are also high which endorses a study conducted by Economist 2020[9].

Psychological aspects of online learning :

Pandemic brought the new normal and students had to shift to online learning safely from home.With different abilities, rural location and varying levels of programs is a challenge in front of educators. Trying to keep students engaged during 
online learning is a challenge faced by educators. Students felt that inability to do peer learning, discussions in various places at institute premises like library, lawns, cafeteria because of lockdown brought their motivation levels little lower. But social media platforms like Whats App, facebook etc. reduced these challenges to quite an extent.

The discussion with students revealed that being in a physical class room is a different feeling and helps them remain more engaged. Figure 6 shows the preference level of the student regarding the mode of learning preferred by them. Most of the students have preferred meeting regularly in classroom setting. The students revealed that they feel more comfortable and have more confidence to open up in remote classrooms as compared to physical ones. Entwistle (1998)[10] emphasized that it the 'three Es' - explanation, enthusiasm and empathy are most likely to evoke a deep learning approach to learn among students. And as per the student preferences, the same can be evoked by keeping them in classroom setting.

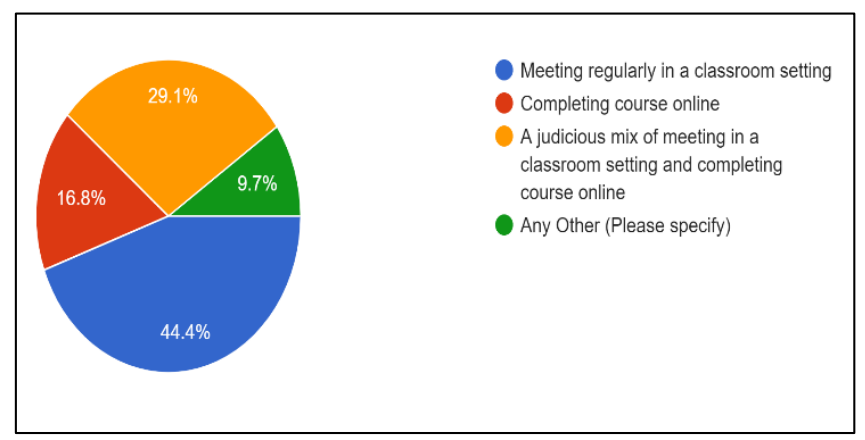

\section{Figure No. 6 : Mode of Learning preferred by the respondents}

Even after the challenges faced, the students tried their level best to adapt to the new normal. When asked to rate the performance they have rated their self-performance as shown in figure 7.Most of them feel that their performance in understanding and applying course content is similar in online learning and physical classroom setting. This indicates that if online teaching is made more engaging then it can easily be implemented in future as well with student satisfaction of the same.

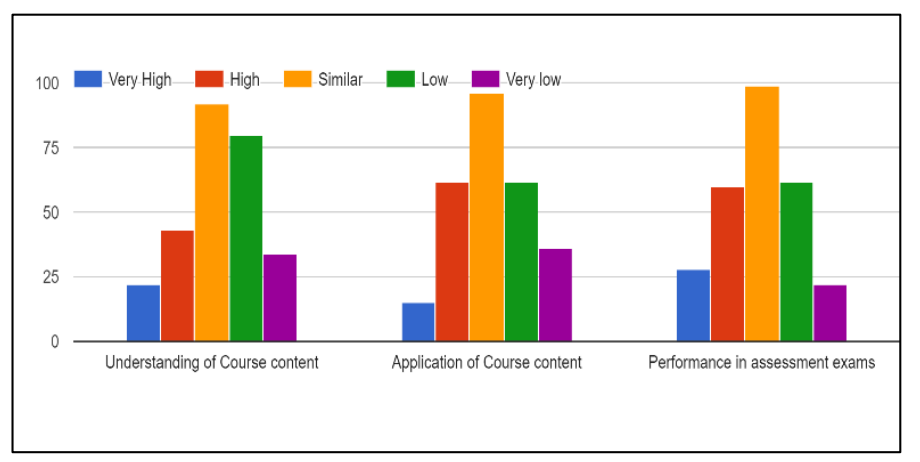

Figure No. 7 : Rating performance during online learning by the respondents

The findings reveal that though online learning was a sudden transition for the students, they have adapted to it successfully with the psychological support from the educators, mentors and their families despite the challenges of missing the environment of a classroom as well as sitting on college campus informally. The discussions also brought in focus that many times the faculty uses videos or audios which help some of them understand better. Some students expect assignments and their assessment to improve their learnings.Learning relies on various psychological processes and mechanisms such as inner drive to understand and perceive new experiences, as well as the motivational desire to explore for positive reinforcement. In order to maximize its outcomes in case of online environments, all psychological aspects that enhance the learning processas mentioned by Wheldall and Riding (2019)[11] must be considered like understanding their learning styles and adapting your pedagogy accordingly.

\section{Conclusion :}

The study was carried out to unmask the student experiences during the sudden transition to online learning during the pandemic of Covid-19. It is found that the students find online learning more convenient and enables regularity in attending the classes with important challenges of technical difficulties, distractions and physical stress. Also, the open discussions revealed that if the classes are made more engaging, online learning can really be a game changer. The authors recommends that the institutes should think of incorporating brief activity sessions like meditation, yoga or music to relieve physical stress( Kassymova et al.,2018) [12]. It is also recommended that, the faculties should understand the psychology of learning, the retention time, the learning styles to make their classes more engaging and fruitful.A good mix of audio, video, assignments and presentations can enable an interactive classroom. Though a number of studies were carried out to understand educator's experiences, the study is unique as it tried to capture the learning experiences along with understanding the psychology of students during the transition. Informal discussion with them revealed that during the online learning they missed the emotional connect with their peers and friends.

The study contributes by identifying the important factors of making online learning more effective and the challenges faced by the learners. This will help the education community to take corrective steps to make the experiences more engaging and meaningful.The study was limited to the theory classes experiences by the students, future research may be extended to practical and projects as well.

Pricncipal component analysis was used by the researchers to identify the important factors, future researchers may use confirmatory factor analysis to validate the results further. 


\section{References}

1. MacKenzie, John (January 2013), "A family empire", BBC History Magazine

2. https://www.who.int/mental_health/media/en/30.pdf? $\underline{\text { ua }=1}$

3. http://wosa.nbaind.org:8081/proceedings/Web\%20pa ge/articles/037.pdf

4. https://swayam.gov.in

5. Nisha, F. and Senthil, V. (2015), "MOOCs: changing trend towards open distance learning with special reference to India", Journal of Library and Information Technology,Vol.35 ,No. 2

6. Bandalaria, M.d.P. (2018), “Open and distance eLearning in Asia: country initiatives and institutional cooperation for the transformation of higher education in the region" ,Journal of Learning for Development, Vol. 5 No. 2,

7. Hemlata Gaikwad, Sushma Kulkarni, Aniket Pardeshi ( 2020), Teachers Perception of Online Teaching during the Covid-19 Pandemic - A Technical Institute Perspective, Yashomanthan, Special Issue COVID-19 Impact On Human Resource Development\& Its Alliance With Business Sustainability, pp 67-72

9.https://lostfocus.eiu.com/?utm campaign=EP2020\%

20-\%20Email \%2047\%20-\%20NEW\%20-

\%20HTML\%20-\%

2020112020\&utm_medium=email\&utm_source=Eloqua \&elqcst $=272$ \&elqcsid $=4331$

10. Entwistle, N. J. (1998). Improving teaching through research on student learning. In J. J. F. Forest (Ed.) University teaching: international perspectives. New York: Garland.

11. Kevin Wheldall ,Richard Riding (2019), Psychological Aspects of Learning and Teaching (Routledge Library Editions: Psychology of Education), Roultledge Press

12. G. K. Kassymova, Kosherbayeva Nurali Aigerim, Sangilbayev S. Ospan, Hans Schachl, Nigel Cox (2018), Stress management techniques for students, International Conference on the Theory and Practice of Personality Formation in Modern Society (ICTPPFMS 2018), Volume: 198 